\title{
Mechanical Properties of Lab Joint Composite Structure of Glass Fiber Reinforced Polymers
}

\author{
Mohammed Y. Abdellah1,2*, Mohamed Q. Kamal'3, Mohammad S. Alsoufi², \\ Nouby M. Ghazaly ${ }^{1}$, G. T. Abdel-Jaber ${ }^{1}$ \\ ${ }^{1}$ Mechanical Engineering Department, Faculty of Engineering, South Valley University, Qena, Egypt \\ ${ }^{2}$ Mechanical Engineering Department, Collage of Engineering and Islamic Architecture, Umm Al-Qura University, Makkah, KSA \\ ${ }^{3}$ Kuwait Oil Company, Ahmadi, Kuwait \\ Email: *mohammed_yahya42@yahoo.com
}

How to cite this paper: Abdellah, M.Y., Kamal, M.Q., Alsoufi, M.S., Ghazaly, N.M. and Abdel-Jaber, G.T. (2017) Mechanical Properties of Lab Joint Composite Structure of Glass Fiber Reinforced Polymers. Materials Sciences and Applications, 8, 553-565.

https://doi.org/10.4236/msa.2017.87038

Received: June 7, 2017

Accepted: July 10, 2017

Published: July 13, 2017

Copyright $\odot 2017$ by authors and Scientific Research Publishing Inc. This work is licensed under the Creative Commons Attribution International License (CC BY 4.0).

http://creativecommons.org/licenses/by/4.0/

\section{Open Access}

\begin{abstract}
Glass fiber composite laminates have competitive properties than monotonic material for their superior mechanical strength. Lab joints in composite structure are of great importance in aerospace and aircraft industry. Therefore, lab joints' strength and failure of composite laminates structure are experimentally investigated. Composites laminates of four different stacking sequences and layup are manufactured using hand layup technique and curing at room temperature. Specimens of unidirectional laminates of $[0]_{8}$ stacking sequence are used to test lamina mechanical properties while $[0 / 90]_{2 s}$, $[0 / 60 / 90]_{s}$ and woven are used to test the mechanical properties of lab joints. Lab joints of single row and double row are produced and tested in bearing using simple mode I test (tension test). The results illustrate that bearing strength of quasi-brittle laminates of $[0 / 60 / 90]_{s}$ has more stability and strength than that of woven glass fiber, then the cross ply laminates of $[0 / 90]_{25}$; this can be attributed to increase of anisotropy of cross ply laminates than other composite laminate structure.
\end{abstract}

\section{Keywords}

Glass Fiber, Bearing Strength, Laminates, Stacking Sequence

\section{Introduction}

Structure of Composite laminates is nowadays having a competitive availability in a lot of applications especially in aerospace, aircraft and Marian industry. Mechanical and fracture properties and joining are main problems facing widespread of such material.

Mohammed et al. [1] measured experimentally and numerically the bearing 
strength of composite GLARE. It measured the bearing strength using single row lab joints while finite element analysis is built to simulate the bearing test.

Mohammed et al. [2] analytically measured fracture toughness of composite laminates quasi-brittle or multilayers laminates form fracture toughness of one direction layer laminates. The model was in good agreement with the experimental model. Many researchers studied and examined the behavior of fastener joints and their effect on specimen geometry and fiber orientation [3] [4].

Xiao and Ishikawa [5] studied mechanical and fracture properties of fastened composite joints. They investigate the polymer matrix cracking of the bearing strength performance. They summarized that failure due to compressive damage involved four stages; damage initiation; damage growth and structural fracture. These damage criteria lead to the experimentally obtained failure modes; fiber micro-buckling; matrix cracking; delamination and out of plane shear cracks. Xiao and Ishikawa [6] analytically and numerically studied the bearing failure and performance of bolted composite joints. They used the finite element progressive damage model. Their results were in good agreement with the experimental data. Hung and Chang [7] extracted a two-dimension accumulation damage model to study effect of clamping pressure and lateral constraint on composite bolted joint.

Camanho et al. [4] investigated the effect of finger tight washer on the damage mechanism of double lab joint. It was concluded that there were four failure modes. These modes are fiber fracture, delamination at loaded hole, matrix cracks and fiber microbuckling. Mohammed et al. [8] used X-FEM procedures to simulate the nominal strength of size effect glass fiber composite laminates; these results were in a good agreement with the experimental results.

The object of the present study is to measure fracture toughness for structure of glass fiber composite laminates using two different specimen standard Compact tensions for cross ply laminates of $[0 / 90]_{2 s}$ stacking sequence and center cracked plate for woven and quasi-brittle laminates of [0/60/90] stacking sequence. Also, it is aimed to find the bearing strength of lab joint manufactured from those types of this material with single and double rows bolts.

\section{Material and Manufacturing}

The manufacturing technique of the laminate composite structure is complicated and varied. It selects the more economic cheapest easy technique which is known as wet hand layup technique proposed by [9] [10]. The method can be summarized as follows: two plates of glass are used; one of them is put asa base and coated using release agent as wax; then a layer of epoxy which has the mechanical characteristic shown in Table 1 is spread over the glass plate with wax. Then a layer of glass fiber is lied over and is impregnated with epoxy resin. Then an epoxy layer is spread over then a glass fiber layers and son on till finished all the laminates layer with its stacking sequences direction as shown in Figure 1. The laminates manufactured of stacking sequence $[0]_{8},[0 / 90]_{2 s},[0 / 60 / 90]_{s}$ and woven of 8 layers. The volume fracture of the composite product is measured 


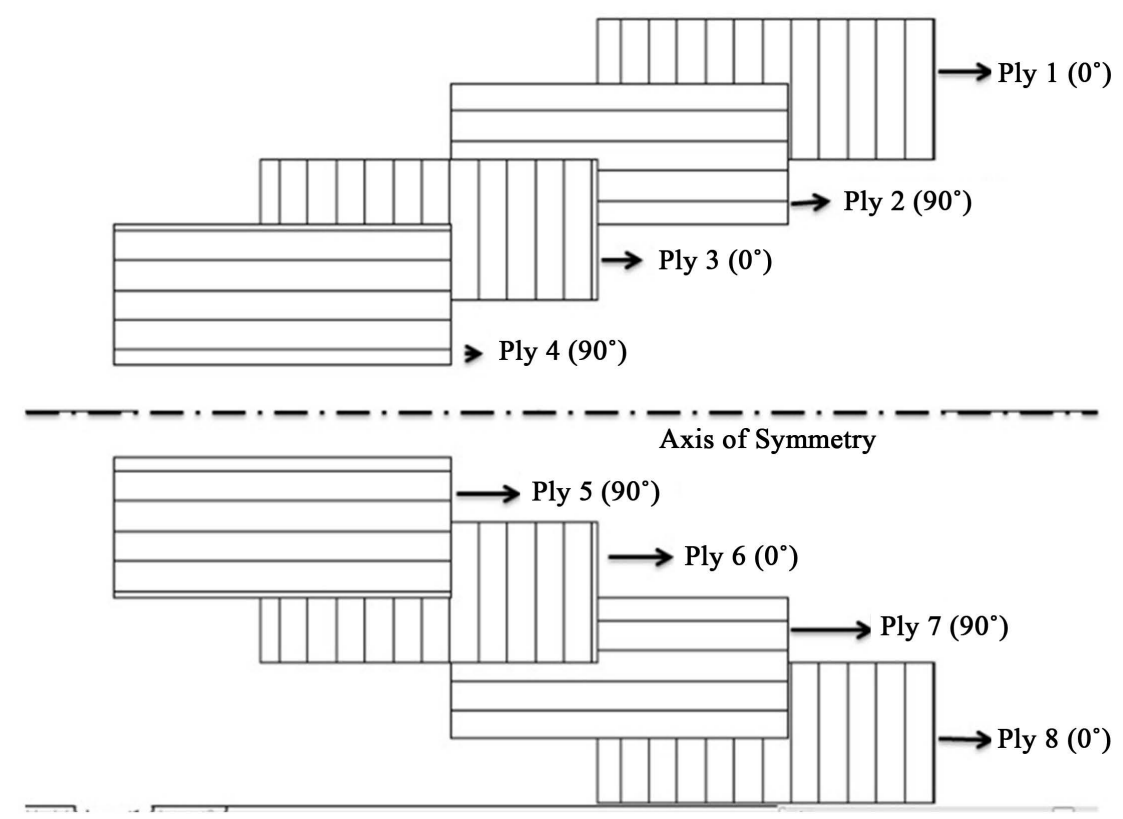

Figure 1. A Schematic sketch for different plies used in manufacturing [0/90 $]_{2 \mathrm{~s}}[10]$.

Table 1. Mechanical and physical properties of E-glass fiber and epoxy resin [12] [13].

\begin{tabular}{ccc}
\hline Properties & E-glass & Kemapoxy (150RGL) \\
\hline Density $\left(\mathrm{kg} / \mathrm{m}^{3}\right)$ & 2540 & $107 \pm 2$ \\
Tensile strength (MPa) & 2000 & $50-100$ \\
Tensile modulus (GPa) & 76 & $1.2-4.5$ \\
Passion ratio & 0.25 & 0.35 \\
In plane shear modulus & 30.8 & 1.24 \\
Failure strain & & 1.7 \\
\hline
\end{tabular}

using ignition removal technique according to ASTM D3171-99 standard [11]. The average value of Vfwas $45 \%$ for unidirectional, quasi-brittle and cross ply laminates while for woven glass fiber it is $40 \%$. The produced plates have thickness of $3 \mathrm{~mm}$ for cross ply $[0 / 90]_{2 \mathrm{~s}}$ and quasi-brittle $[0 / 60 / 90]_{s}$ and 2.2 for woven laminates.

\section{Mechanical Properties}

\subsection{Tensile Strength}

Tension test is carried out on all glass fiber reinforced epoxy laminates according to ASTM D3039 tests standards [14]. The tensile specimen is of the dimension shown in Figure 2. All tests are carried out at a universal testing machine (Model Machine WDW-100) of normal load capacity $200 \mathrm{kN}$ and at a controlled speed of $2 \mathrm{~mm} / \mathrm{min}$. The test specimens are unnotched to determine the unnotched tensile strength. The unidirectional laminates $[0]_{8 \mathrm{~s}}$ is used to find the lamina elastic constant according to that in [10]. The elastic content obtained from these types of laminates is illustrated in Table 2. 


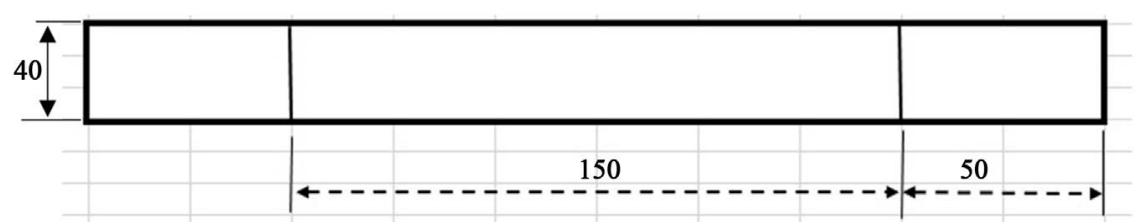

Figure 2. Un notch composites standard specimen plate (dim. in mm).

Table 2. Ply elastic properties.

\begin{tabular}{cc}
\hline property & Mean value \\
\hline Longitudinal young’s modulus, $\mathrm{E}_{1}(\mathrm{GPa})$ & 27 \\
Transverse young's modulus, $\mathrm{E}_{2}(\mathrm{GPa})$ & 5.3 \\
In-plane shear modulus, $\mathrm{G}_{12}(\mathrm{GPa}),( \pm 45$ shear test $)$ & 1.24 \\
Major passion ratio, $\mathrm{v}_{12}$ & 0.31 \\
Longitudinal strength $\left(\mathrm{X}_{\mathrm{t}}\right), \mathrm{MPa}$ & 645 \\
Transverse $\left(\mathrm{Y}_{\mathrm{t}}\right), \mathrm{MPa}$ & 15 \\
\hline
\end{tabular}

\subsection{Fracture Toughness Test}

Fracture toughness measuring has a marked intensity in composite laminates application. Fracture toughness of material is considered a crack resistance parameter. Fracture toughness tests are carried out using two stander specimen shape namely as; compact tension (CT) and center crack plate tension specimens. The Compact tension specimen is performed with dimension shown in Figure 3(a) [15] to study fracture toughness of fiber tension in longitudinal direction of cross ply laminates $[0 / 90]_{2 s}$. These test is carried out according to ASTM D 5045 [16] stander test method. Load is applied through the two loading pins, during the test load and in line displacement with the load is measured and recorded. The crack length at which the failure occurs (at peak load) is measured using optical observation through graduated scale over the crack path. For quasi-brittle $[0 / 60 / 90]_{s}$ laminates and for laminates with woven glass fiber center crack plate tension specimens are used according to Soutis-Flick model [17] to measure the surface release energy of such hybrid composite laminates. The center crack plate specimen test is simple and can be summarized as follows; five specimens with dimension shown in Figure 3(b) with center crack length $(2 \mathrm{a})=$ $15 \mathrm{~mm}$ is loaded in tension until failure. During test the load and displacement are recorded.

\subsection{Bearing Strength}

Joining of composite structure members is a design complicated problem, this can be due to the joint passes through geometry of structure and material discontinuity [1]. The double lab joint testing set up which is shown in Figure 4 is manufactured for purpose of double lab joint bearing strength measuring. The test device contains three steel plates, two of them for holding the specimens with bolts and the other one is loading plate member. The composite specimens 


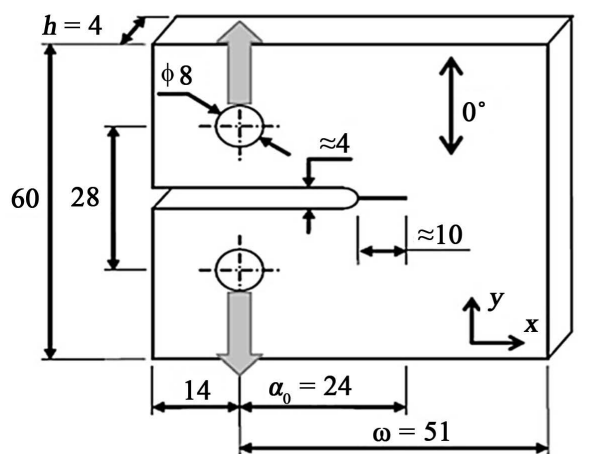

(a)

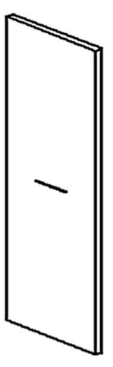

Figure 3. Fracture toughens sample, (a) Compact tension test sample with $t=3$, or 10 [15] and (b) Canter crack specimen [10].
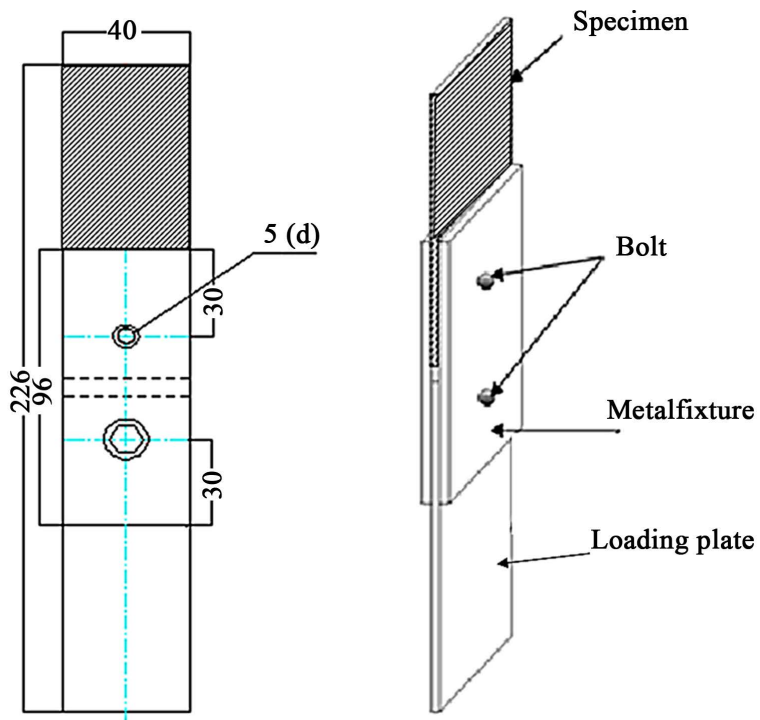

Figure 4. Testing setup of bolted joint specimens with dimensions in $\mathrm{mm}$ [1].

are of rectangular cross section $40 \mathrm{~mm}$ width and $80 \mathrm{~mm}$ length with hole of 5 $\mathrm{mm}$ at $20 \mathrm{~mm}$ from plate end.

The test is performed at universal testing machine ((model WDW-100) of load capacity $(200 \mathrm{kN})$, at cross head speed is $2 \mathrm{~mm} / \mathrm{min}$. The set up shown in Figure 4 is gripped in the machine Jaws. Bearing strength is defined as the bearing load when pin relative displacement is deformed to (4\%) the pin diameter [1]. The average bearing strength, is expressed as [5]:

$$
S_{b}^{4 \%}=\frac{P_{4 \% d}}{d \cdot t}
$$

Whereas, ultimate bearing strength is expressed as:

$$
S_{b}^{U l t}=\frac{P_{\max }}{d \cdot t}
$$

$\left(P_{\max }\right)$ is the maximum load, $\mathrm{N},\left(P_{4 \%}\right)$ is the bearing load, $\mathrm{N},(d)$ is the pin diameter, $\mathrm{mm},(t)$ is thickness of specimen, $\mathrm{mm}$. 


\section{Result and Discussion}

\subsection{Un-Notch Tensile Strength}

Figure 5 shows stress strain curve for varying stacking sequences. It is shown that cross ply laminates $[0 / 90]_{2 s}$ has higher tensile strength than that of quasi-brittle laminates $[0 \mathrm{t} 60 / 90]_{s}$. laminates with woven fiber has lower strength. These results are due to shear effect of 60-degree ply in the quasi-brittle laminates which make the load distributed through that direction and shear stress produced. The woven fiber in laminates makes stat of complex and stat of stress through the fiber direction which led to reduce of the laminate strength. It is observed that the curves have fluctuation due to fiber breaking. The modes of failure are shown in Figure 6 where net tension failure mode is observed in cross ply laminates, and a delamination crack through thickness occurs in quasi-brittle specimen of $[0 / 60 / 90]_{s}$ and in laminates with woven fiber, this can be attributed to shear stress induced in the laminates structure.

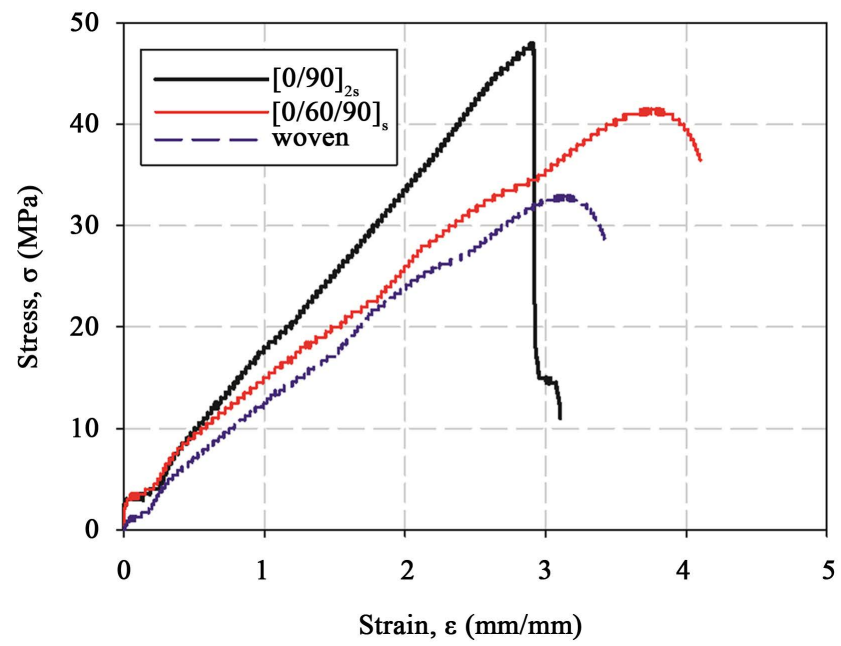

Figure 5. Stress strain curve of composite laminates with varying stacking sequences.

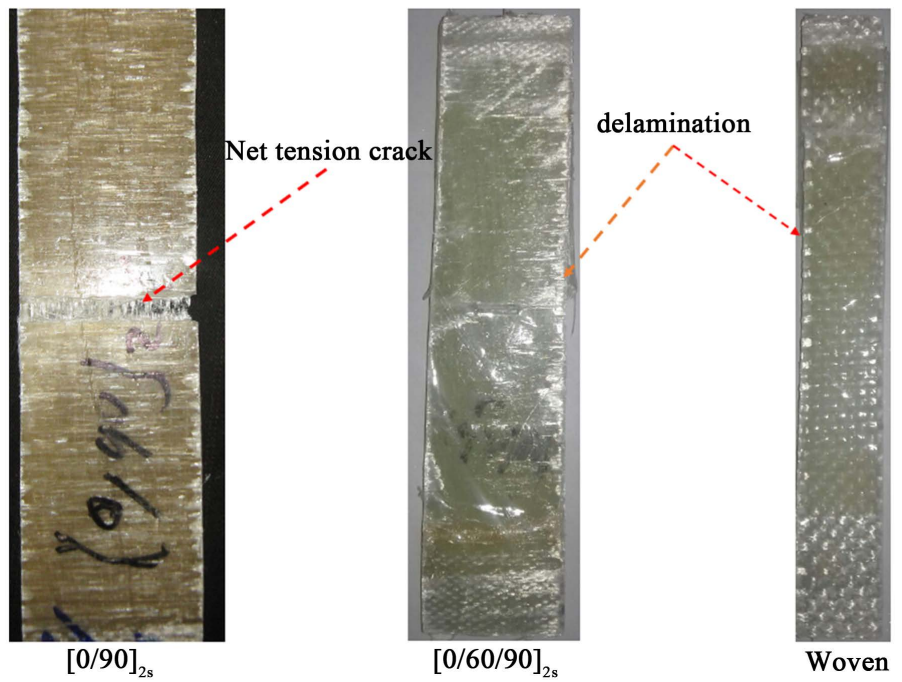

Figure 6. Modes of failure of unnotched composite plate. 


\subsection{Fracture Toughness Test}

Figure 7 illustrates load-displacement curves of compact tension test for cross ply laminates $[0 / 90]_{2 s}$, the point of fracture load is selected to be the point of intersection of $5 \%$ lower than the initial P $-\delta$ curve (the $5 \%$ secant line) according to ASTM D 5045 [16] stander test method. The average fracture loads $\left(P_{Q}\right)$ value at $5 \%$ secant obtained from curves of cross ply panels is $(1407.34 \mathrm{~N})$, and the value of crack length (a) measured from cross ply [0/90 $]_{2 \mathrm{~s}}$ panels is approximately $(0.9 \mathrm{~mm})$ then substituting these results into Equations (3) and (4).

$$
\begin{gathered}
K_{I C}=\frac{p_{Q}}{h \sqrt{w}} f\left(\frac{a}{w}\right) \\
f\left(\frac{a}{w}\right)=\frac{2+\frac{a}{w}}{\left(1-\frac{a}{w}\right)^{1.5}}\left[0.886+4.64\left(\frac{a}{w}\right)-13.32\left(\frac{a}{w}\right)^{2}+14.72\left(\frac{a}{w}\right)^{3}-5.6\left(\frac{a}{w}\right)^{4}\right]
\end{gathered}
$$

Results of calculating the values of the average fracture toughness $\left(K_{I C}\right)$ are shown in Table 3 with standard deviation.

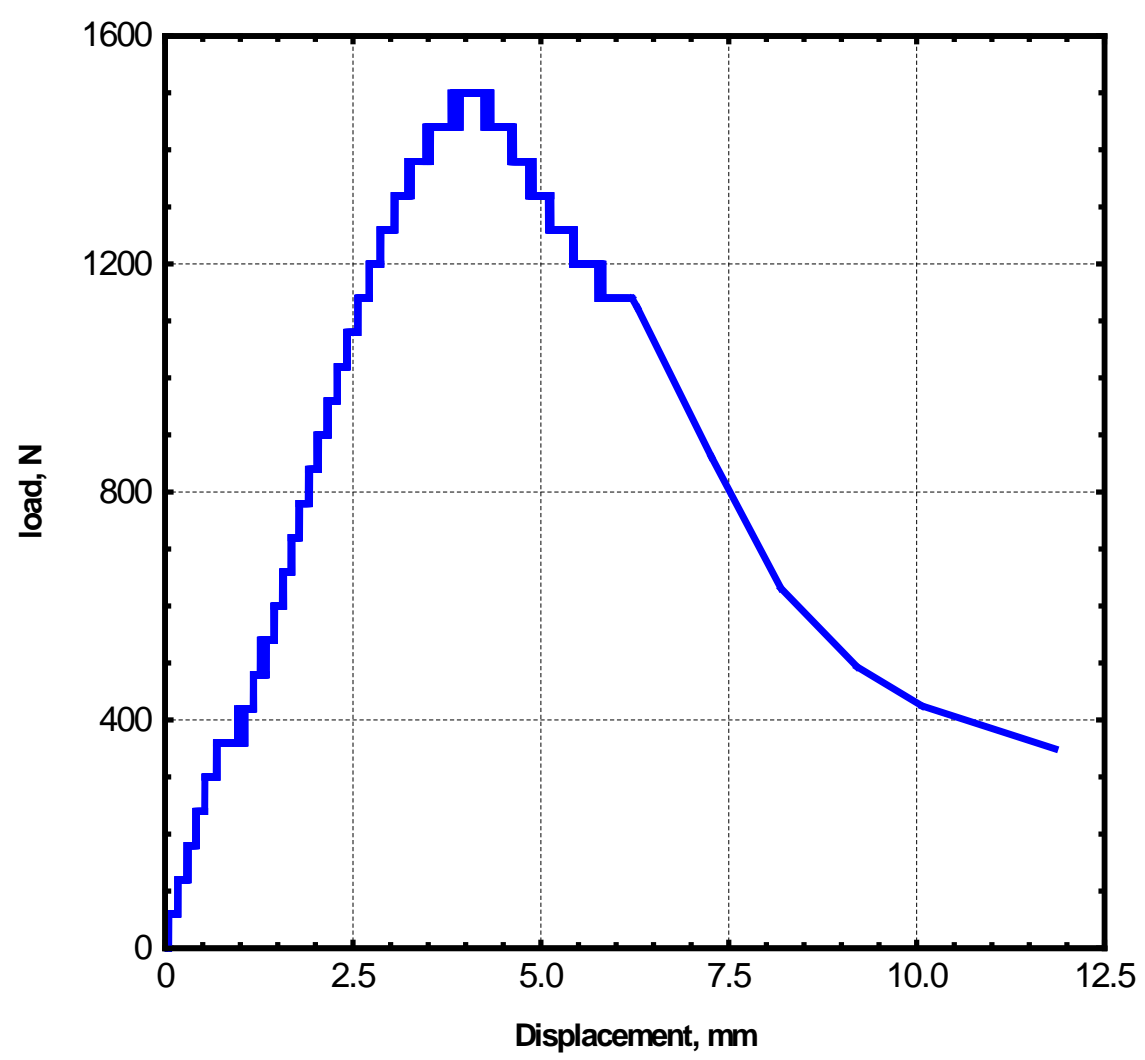

Figure 7. Load displacement curve of compact tension test of $[0 / 90]_{2 s}$.

Table 3. Fracture properties of composts laminates.

\begin{tabular}{ccc}
\hline & \multicolumn{2}{c}{ Fracture Toughness, $K_{I C}\left(\mathrm{MPa} \cdot \mathrm{m}^{1 / 2}\right)$} \\
\hline Specimen & Average & $\mathrm{STDV}$ \\
{$[0 / 90]_{2 \mathrm{~s}}$} & 40 & 2 \\
\hline
\end{tabular}


Figure 8 shows the images of $[0 / 90]_{2 s}$ panels specimens after applied compact tension test. Crack length (a) in the $[0 / 90]_{2 s}$ panels was observed on the surface and there is fiber bridging in laminates facings onto $[0 / 90]_{2 s}$ panels core specimen but fiber of cross ply laminates panels is very weak so that observed from Figure 8 and results in Table 3, that laminates facings give the cross-ply panels higher fracture properties.

Figure 9 shows stress strain curves results for Center cracked test on [0/60/90] panels and woven epoxy panel, observed that curves o Five specimens were used

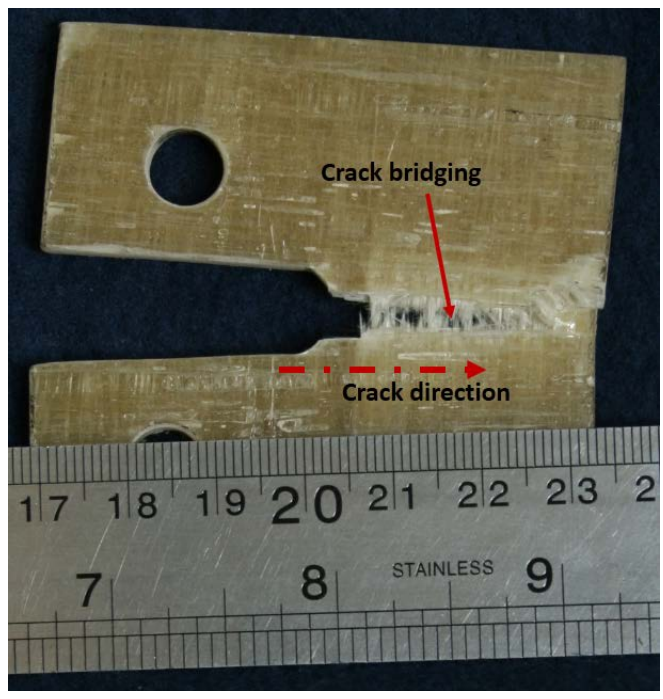

Figure 8. The image of compact tension test for $[0 / 90]_{2 s}$.

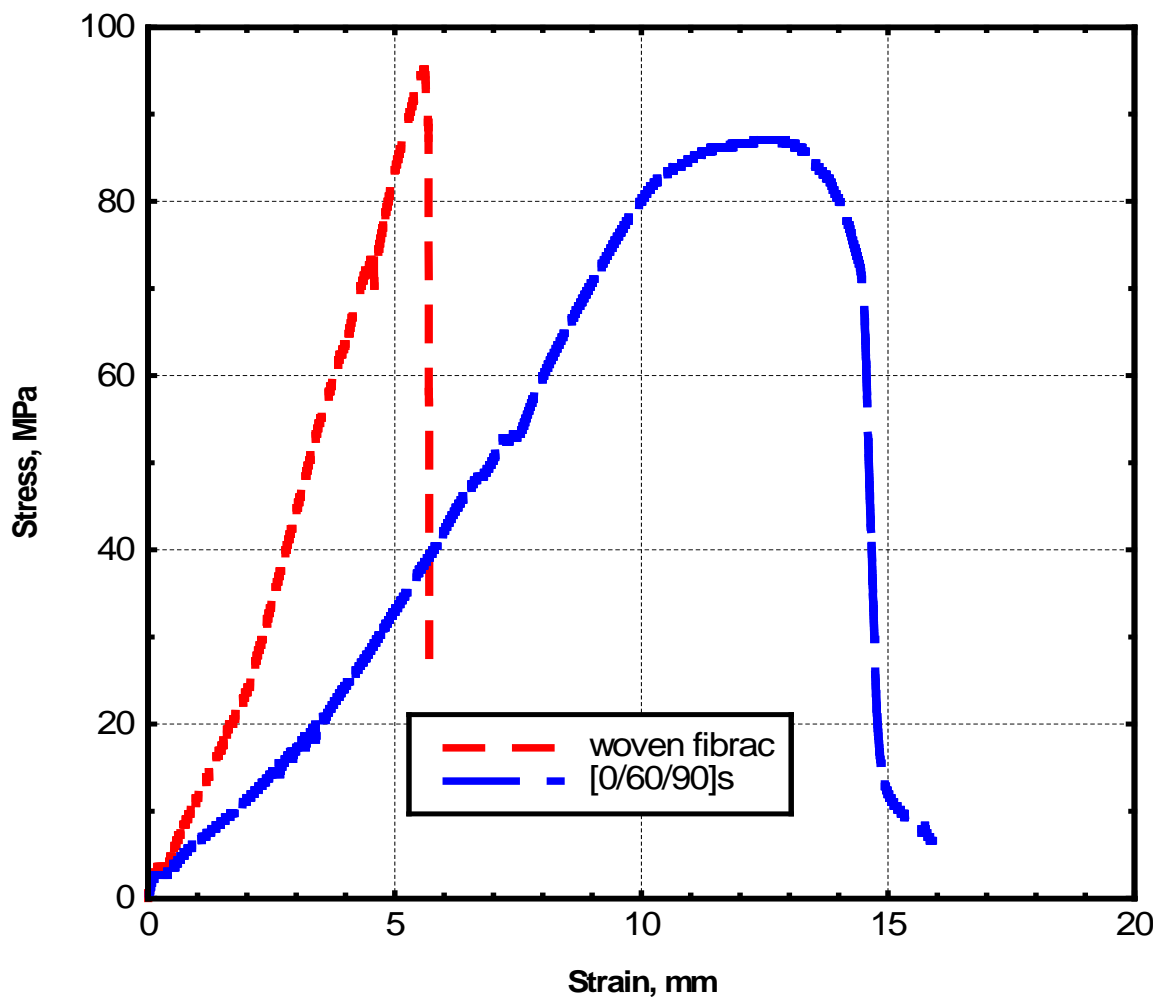

Figure 9. Stress strain curves specimens for Centre cracked test. 
Width $W=45 \mathrm{~mm}$, gauge section length- $L=90 \mathrm{~mm}$, thickness- $t=2.2$ for woven epoxy and $t=3$ for [0/60/90] panel. The average value of failure stress $(\sigma)$ was calculated for all specimens where (95), (97) of [0/60/90] panels and woven panel respectively; (2a) is center crack length equal $(15 \mathrm{~mm})$ substituting these results into Equation (5) the result is the value of the fracture toughness $\left(K_{I C}\right)$, in Table 4 shows the average fracture toughness and standard deviation of [0/60/90] panels and woven panel

$$
K_{I C}=\sigma \sqrt{\pi a} \sqrt{\sec \left(\frac{\pi a}{w}\right)}
$$

The curve obtained from a compact specimen has a longer length compared to one obtained from center cracked specimen, because the gradient of $(K)$ stress intensity factor $(K)$ in a compact specimen is decreasing whereas the gradient of $(K)$ in center cracked specimen is increasing [18]. So, that, the stress intensity factor $(K)$ for compact tension using for mechanical design and the stress intensity factor $(K)$ for center cracked using for standard of material.

Figure 10 shows the images of (a) [0/60/90] sanels and (b) woven specimens after applied Center cracked test. It is observed that delamination occurs in [0/60/90 $]_{\text {s }}$ panel's core of composite. The delamination occurs probably; due to that weaken of epoxy resin adhesive used in manufacturing the laminates panel and there was net tension in laminates panel's specimens.

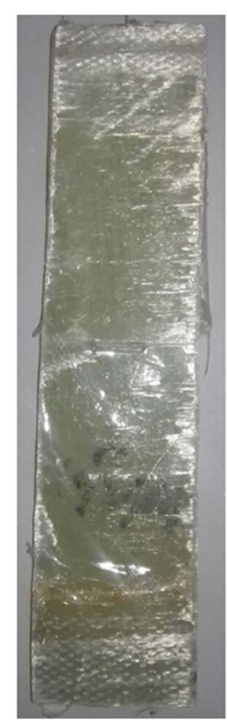

$[0 / 60 / 90]_{s}$

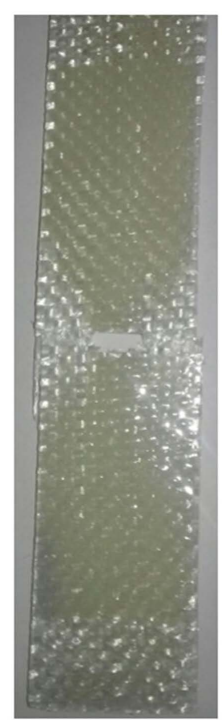

Woven

Figure 10. Mode of failure for composite plates.

Table 4. The values of fracture toughness for Center cracked test

\begin{tabular}{ccc}
\hline & Fracture Toughness, $K_{I C}\left(\mathrm{MPa} \cdot \mathrm{m}^{1 / 2}\right)$ \\
\hline Specimen & Average & STDV \\
{$[0 / 60 / 90]_{\mathrm{s}}$} & 30 & 2 \\
woven & 25 & 1 \\
\hline
\end{tabular}




\subsection{Bearing Strength}

Load displacement relation for bearing strength test for both single row and double row lab joints are illustrated in Figures 11-13. It is clearly observed that as the rows of bearing increase the load increase; this can be attributed to increasing of material strength facing each bolt. While, it is shown that with increasing bearing diameters the load decreases, this is due to increasing of size effect and nosh sensitivity with increasing stress intensity factor Ks around these holes [2] [17] [19] [20]. Bearing strengths of the lab joint with double rows are

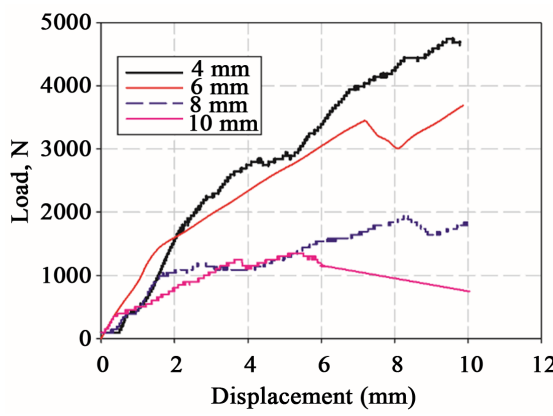

(a)

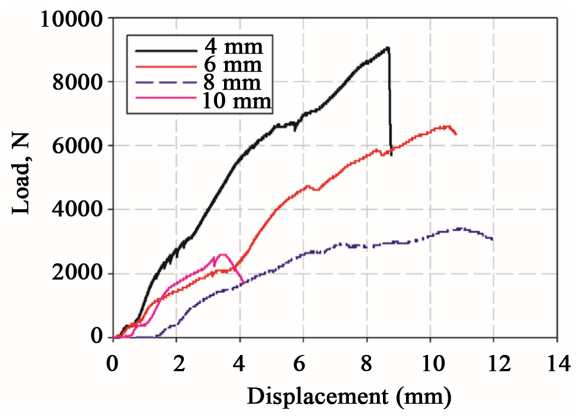

(b)

Figure 11. Load-displacement of the bolt joint $[0 / 90]_{2 \mathrm{~s}}$ (a) single row bolted joint; (b) double row bolted joint.

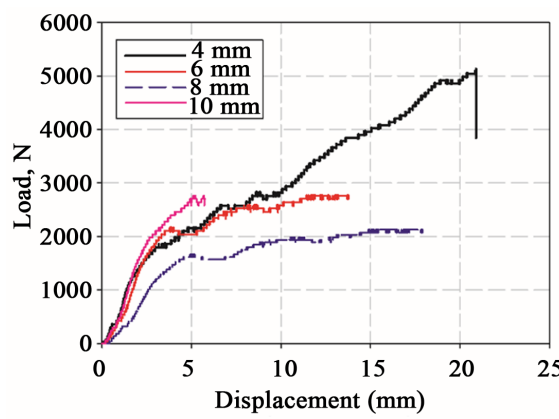

(a)

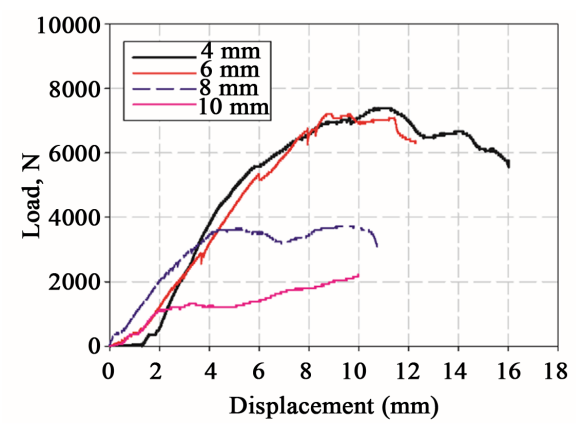

(b)

Figure 12. Load-displacement of the bolt joint $[0 / 60 / 90]_{s}$ (a) single row bolted joint; (b) double row bolted joint.

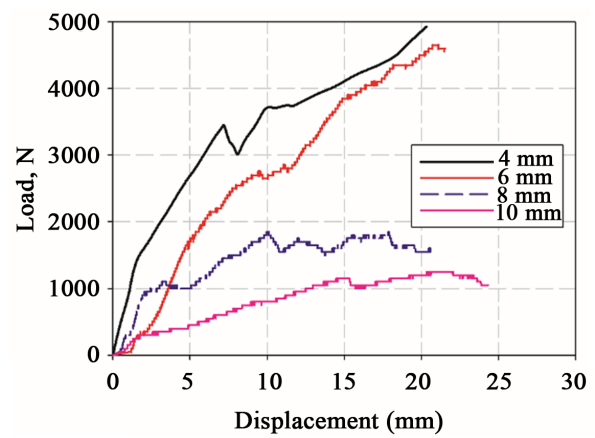

(a)

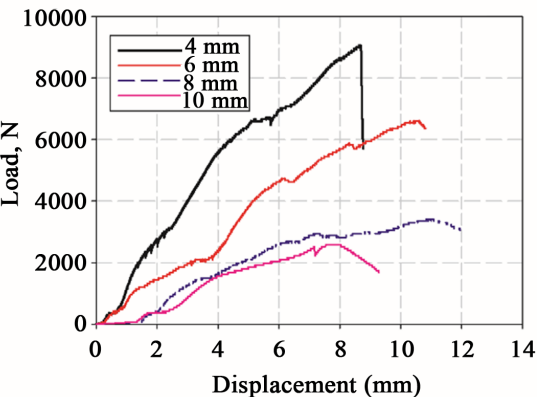

(b)

Figure 13. Load-displacement of the bolt joint woven glass fibre (a) single row bolted joint; (b) double row bolted joint. 
higher than that of single row for all testing specimens with each stacking sequences as shown in Figures 14-16. This is can be results of increasing load which means that the designer needs to take the types of lab joint into account to make the laminates material withstand the excess load of the bearing bolts. Modes of failure is tension mode and tearing for all specimens with fiber breaking and matrix cracking as shown in Figure 17 and Figure 18.

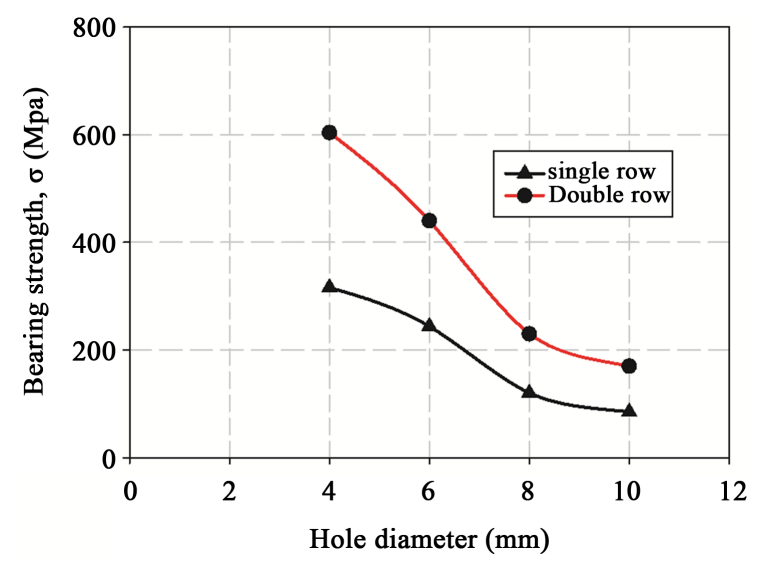

Figure 14. Bearing strength of lab joint of $[0 / 90]_{2 s}$.

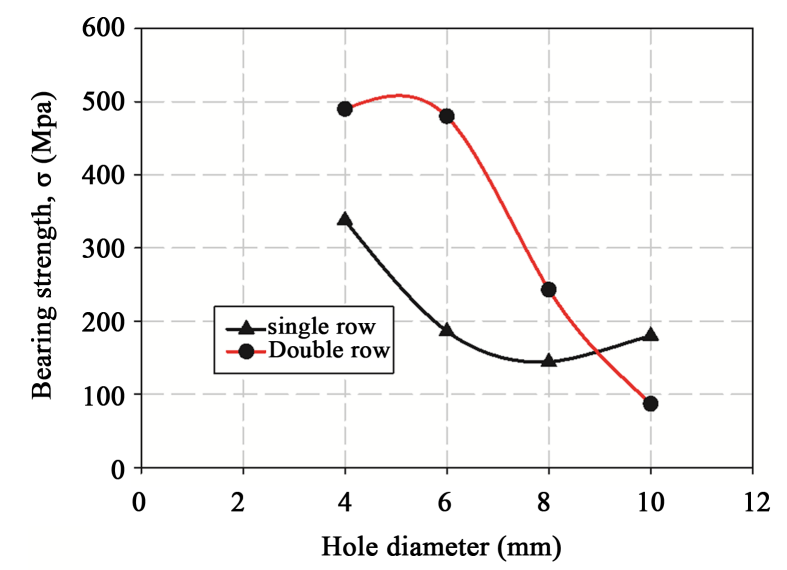

Figure 15. Bearing strength of lab joint of $[0 / 60 / 90]_{s}$.

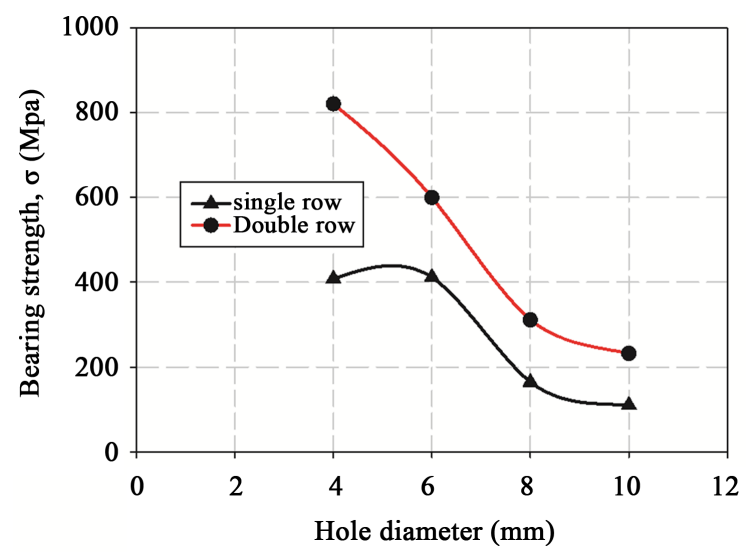

Figure 16. Bearing strength of lab joint of woven. 


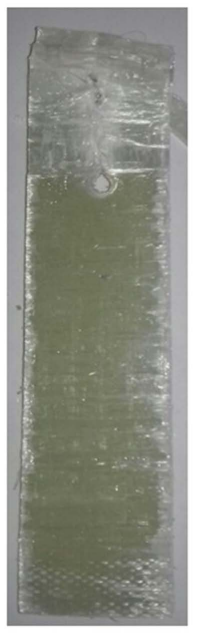

$[0 / 60 / 90]_{s}$

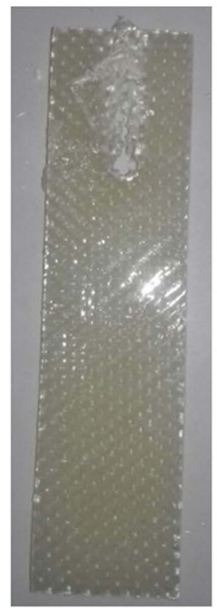

Woven

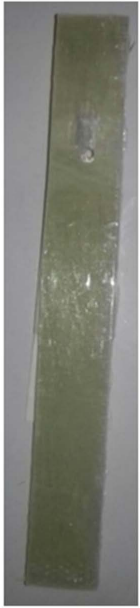

$[0 / 90]_{\mathrm{s}}$

Figure 17. Mode of failure in composite plate in the bolt joint specimens single row.

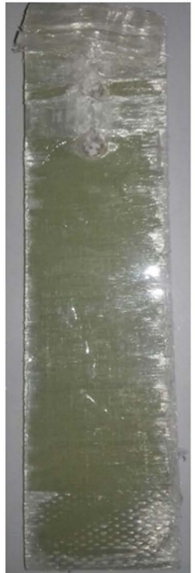

$[0 / 60 / 90]$

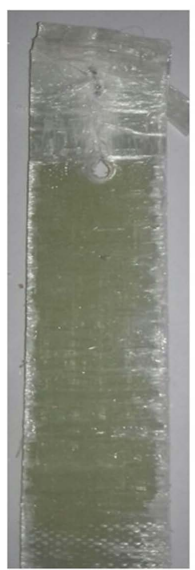

$[0 / 90]_{s}$

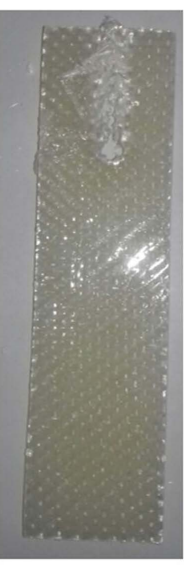

Woven

Figure 18. Mode of failure in composite plate in the bolt joint specimens double row.

\section{Conclusion}

Glass fiber composite laminates of varying stacking sequence are manufactured with good compatibility and cheapest cost using hand layup technique. Fracture toughness of the composite laminates is measured using compact tension and center crack plate specimens. The measured fracture toughness illustrates that cross-ply laminates have increasing fracture toughness. The bearing strength for lab joints of composite laminates is measured for single and double rows bolts; it is measured that specimen with double rows needs extra load to withstand the action of the two-bearing induced through the material joints.

\section{References}

[1] Abdellah, M.Y., Hassan, M.K., Mandourah, T. and Mohamed, A.F. (2016) Bearing Strength and Failure Behavior of Bolted GLARE Joints. International Journal of Mechanical \& Mechatronics Engineering IJMME-IJENS, 16, 54-63.

[2] Mohammed, Y., Hassan, M.K. and Hashem, A. (2014) Analytical Model to Predict 
Multiaxial Laminate Fracture Toughness from 0 Ply Fracture Toughness. Polymer Engineering \& Science, 54, 234-238. https://doi.org/10.1002/pen.23552

[3] Hart-Smith, L. (1976) Bolted Joints in Graphite-Epoxy Composites. DTIC Document.

[4] Camanho, P.P. and Matthews, F. (1997) Stress Analysis and Strength Prediction of Mechanically Fastened Joints in FRP: A Review. Composites Part A: Applied Science and Manufacturing, 28, 529-547. https://doi.org/10.1016/S1359-835X(97)00004-3

[5] Xiao, Y. and Ishikawa, T. (2005) Bearing Strength and Failure Behavior of Bolted Composite Joints (Part I: Experimental Investigation). Composites Science and Technology, 65, 1022-1031. https://doi.org/10.1016/j.compscitech.2005.02.011

[6] Xiao, Y. and Ishikawa, T. (2005) Bearing Strength and Failure Behavior of Bolted Composite Joints (Part II: Modeling and Simulation). Composites Science and Technology, 65, 1032-1043. https://doi.org/10.1016/j.compscitech.2004.12.049

[7] Hung, C.-L. and Chang, F.-K. (1996) Bearing Failure of Bolted Composite Joints. Part II: Model and Verification. Journal of Composite Materials, 30, 1359-1400. https://doi.org/10.1177/002199839603001204

[8] Mohammed, Y., Hassan, M.K. and Hashem, A. (2012) Finite Element Computational Approach of Fracture Toughness in Composite Compact Tension Specimen. International Journal of Mechanical and Mechatronics Engineering, 12, 57-61.

[9] Khashaba, U.A. (2004) In-Plane Shear Properties of Cross-Ply Composite Laminates with Different Off-Axis Angles. Composite Structures, 65, 167-177.

[10] Mohammed, Y., Hassan, M.K., El-Ainin, H. and Hashem, A. (2014) Effect of Stacking Sequence and Geometric Scaling on the Brittleness Number of Glass Fiber Composite Laminate with Stress Raiser. Science and Engineering of Composite Materials, 21, 281-288. https://doi.org/10.1515/secm-2013-0038

[11] Standard, A. (2011) D3171, Standard Test Methods for Constituent Content of Composite Materials. West Conshohocken.

[12] Jones, R.M. (1998) Mechanics of Composite Materials. CRC Press, Boca Raton.

[13] Mallick, P.K. (1997) Composites Engineering Handbook. CRC Press, Boca Raton.

[14] Standard, A. (1995) Standard Test Method for Tensile Properties of Polymer Matrix Composite Materials. ASTM D3039/D 3039M.

[15] Pinho, S.T., Robinson, P. and Iannucci, L. (2006) Fracture Toughness of the Tensile and Compressive Fibre Failure Modes in Laminated Composites. Composites Science and Technology, 66, 2069-2079. https://doi.org/10.1016/j.compscitech.2005.12.023

[16] Standard, A. (1996) Standard Test Methods for Plane-Strain Fracture Toughness and Strain Energy Release Rate of Plastic Materials. D5045-96.

[17] Hassan, M.K., Mohammed, Y., Salem, T. and Hashem, A. (2012) Prediction of Nominal Strength of Composite Structure Open Hole Specimen through Cohesive Laws. International Journal of Mechanical \& Mechatronics Engineering IJMMEIJENS, 12, 1-9.

[18] Ward, I.M. and Hadley, D.W. (1993) An Introduction to the Mechanical Properties of Solid Polymers. John Wiley \& Sons Ltd.; John Wiley \& Sons, Inc., Hoboken.

[19] Mohammed, Y., Hassan, M.K., El-Ainin, H.A. and Hashem, A.M. (2015) Size Effect Analysis of Open-Hole Glass Fiber Composite Laminate Using Two-Parameter Cohesive Laws. Acta Mechanica, 226, 1027-1044.

[20] Soutis, C., Curtis, P. and Fleck, N. (1993) Compressive Failure of Notched Carbon Fibre Composites. Proceedings of the Royal Society of London A: Mathematical, Physical and Engineering Sciences, 241-256.

https://doi.org/10.1098/rspa.1993.0014 
Submit or recommend next manuscript to SCIRP and we will provide best service for you:

Accepting pre-submission inquiries through Email, Facebook, LinkedIn, Twitter, etc. A wide selection of journals (inclusive of 9 subjects, more than 200 journals)

Providing 24-hour high-quality service

User-friendly online submission system

Fair and swift peer-review system

Efficient typesetting and proofreading procedure

Display of the result of downloads and visits, as well as the number of cited articles Maximum dissemination of your research work

Submit your manuscript at: http://papersubmission.scirp.org/

Or contact msa@scirp.org 